\author{
organised jointly by the \\ Indian Olympic Association and the Indian Association of Sports Medicine \\ at the Netaji Subhas National Institute of Sport, Patiala, India \\ from 5th November, to 25th November, 1979.
}

After the difficulties in communication and arrangements which made necessary the postponement of this Course, I am pleased to report that the Course took place as arranged and that it appears to have been successful.

The general arrangements for the Course were entirely satisfactory and the administration was almost flawless. There was a minor problem in relation to transport of one of the lecturers (which was not the immediate responsibility of the organiser in Patiala) and the only other criticism I would make is that some of the Indian doctors present had previously had an opportunity of attending an FIMS course. I would have thought that for the future, in view of the relatively limited number of positions available on these courses and the demand for them, it would be sensible to accept as students only those who had never previously attended an FIMS course.

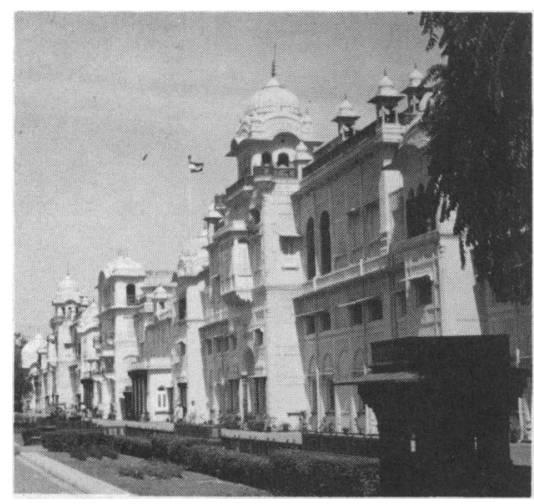

Patiala - the old Maharaja's Palace, now the National Institute of Sport.

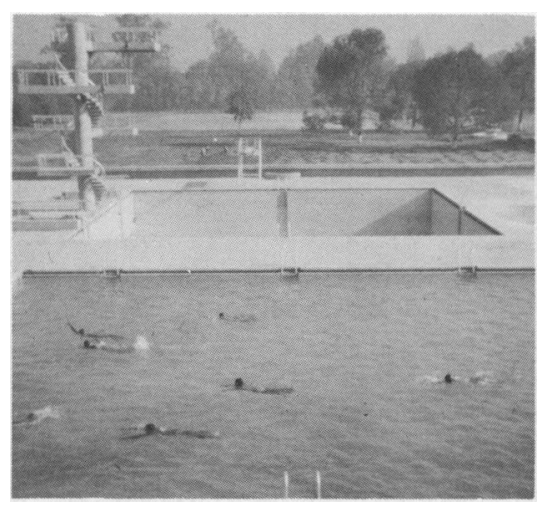

The swimming pool - N.I.S. Patiala.

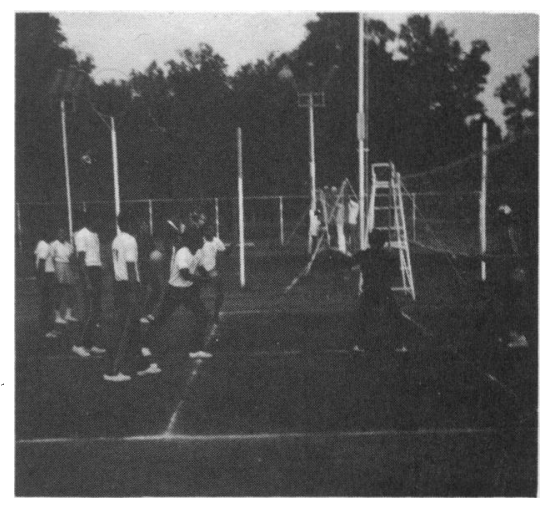

Volleyball practice.

The faculty members were Dr. J. G. P. Williams, Consultant in Rehabilitation Medicine, and Secretary General of the FIMS, Professor Eide Lübs, Institute of Sports Medicine, Kassel, West Germany, Dr. Henry Robson, Editor of the British Journal of Sports Medicine and Surgeon Commander Dermot Crean, Specialist in Rehabilitation and Sports Medicine to the Royal Navy. Guest lecturers included Dr. B. K. Annand, (Neuro physiology and Sports), Surgeon Rear Admiral Malhotra (Physiology of Sport in adverse environment) and Professor Kurt Tittel from Leipzig (Sports Anthropometry) who was present at the expense of the government of the German Democratic Republic.

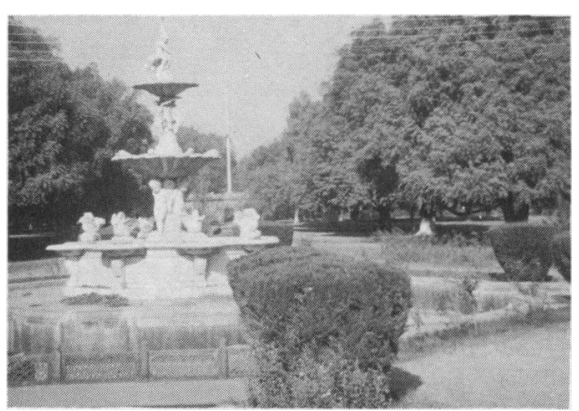

A fountain in the palace grounds, which made a good outdoor lecture venue.

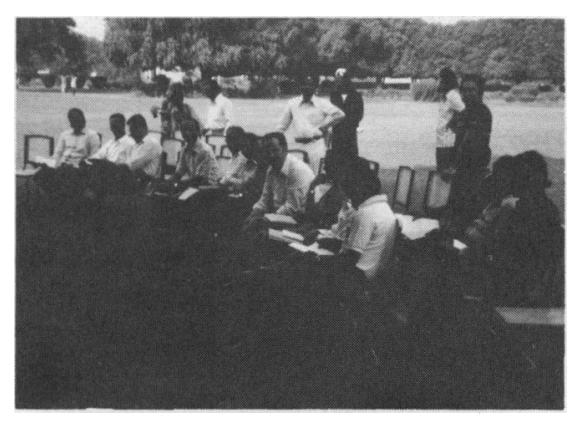

"Under a tree" - an alternate lecture venue. 
The curriculum followed in general the pattern of the FIMS basic course of Sports Medicine with additional lectures, and a valuable part of the Course was a series of seminars in which the students themselves presented their own material for discussion by their fellow students and by the lecturers. There was in addition a satisfactory cultural and recreational programme and the National Institute of Sport in Patiala provided excellent facilities for physical recreation.

Altogether, twenty-six doctors completed the Course officially and there was one other doctor who participated as an unofficial student. There were also a number of doctors from local Institutes who attended some of the lectures and lectures were also attended by coaches from the National Institute of Sport.

Eleven countries were represented as follows:

$\begin{array}{ll}\text { India } & \text { Thailand } \\ \text { Indonesia } & \text { The Peoples' Republic of China } \\ \text { Nepal } & \text { Bangladesh } \\ \text { Burma } & \text { Syria } \\ \text { Bahrain } & \text { Israel }\end{array}$

Qatar

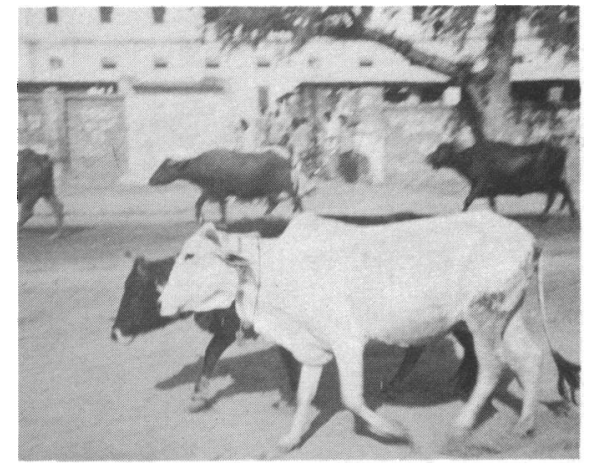

A main street in Patiala City.

At the conclusion of the Course, the students were submitted to an examination, using the multiple choice questionnaire with loading of zero or minus marks for incorrect answers. The pass level was set at $50 \%$, with a discount of $5 \%$ to cover any problems relating to languages. Four students, all from India, failed to reach the pass standard in the examination. All others passed, and the best students were jointly one from India and one from the Peoples' Republic of China. All students (pass or fail) managed to achieve a greater than $50 \%$ level of correct answers. After the completion of the Course diplomas were presented and those students who had not previously attended FIMS courses were admitted to Associate Membership of the International Federation of Sports Medicine.

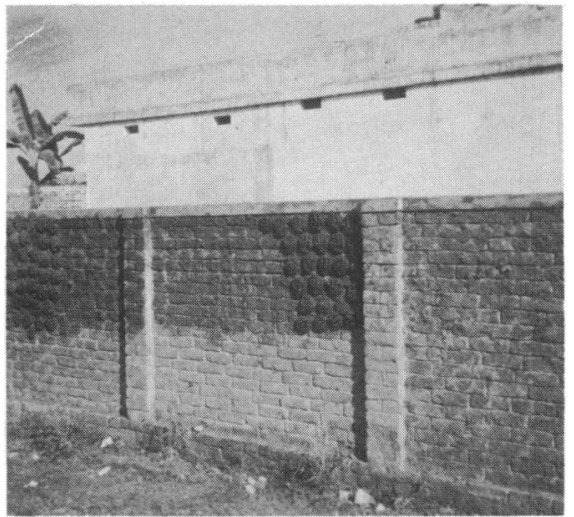

Cow dung drying out for fuel. Many crops have a poor yield through shortage of fertilisers.

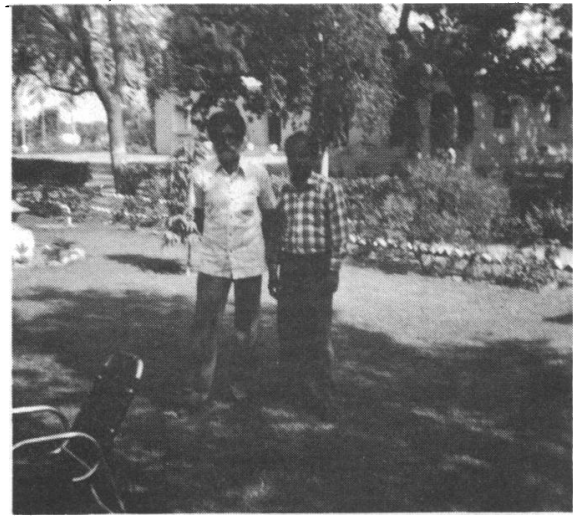

A swimming coach and the Sikh driver from the N.I.S. The driver, once one of "Monty's" tank commanders at El Alamein, managed to get along the crowded Grand Truck Road with little delay.

Following the Course a questionnaire was submitted to all students, requesting their views on the organisation and management of the Course, standard of lecturers, etcetera. The general opinion was that the three week Course was a little too long, but it is understood that this three week period is the period selected for standard Olympic Solidarity Courses. Some of the candidates felt that the material was a little basic, but it is interesting to note that these candidates were in fact those who tended to score lowest in the examination! The general standard of the lectures 
appeared to be satisfactory. There were difficulties reported with two lectures in respect of language - this emphasises the point that the lecturers for courses of this type must be really experienced and fluent in the vernacular of the course. It is interesting that Professor Lübs presented more difficulty to the Indians than to the students from other countries (previously in Thailand Professor Lübs had presented no difficulty in respect of understanding). It therefore appears that the problem may in fact be less one of fluency than of accent. The apparent difficulty was not reflected in the scoring in the examination papers, so that although students may have had problems with the lecturers there were no apparent difficulties with understanding of the actual material.

It is possible that some of the difficulties in the examination were accounted for by the unfamiliarity of the students with multichoice type of examination, particularly in a tendancy to guess at answers rather than to leave blanks incorrect answers being frequently penalised with minus marks. In other respects the students appeared to have enjoyed the Course enormously and it is a pleasure for me to report that despite some difficulties early on, a very happy and relaxed atmosphere developed among the students despite the disparity in their countries of origin. By the end of the Course there was a free mixture of students with no constraints, a matter for which the organisers should take credit and which is of course the whole essence of the Olympic movement and indeed of the International Federation of Sports Medicine.

\section{SOME IMPRESSIONS OF INDIA AND THE SPORTS MEDICINE COURSE}

\section{H. E. ROBSON}

When asked to join the lecturing team for the Asian Sports Medicine course reported by Williams above, I was also invited to visit the Hindu University at Varanasi (Benares), and see the Sports Medicine and Pulmonary Physiology Unit in the Institute of Medical Sciences. Having had difficulties in communication due to postal delays, and aware that though the British had introduced bureaucracy into India, the Indian officials had "improved" it beyond all recognition, I was prepared for absolute administrative chaos, so was delighted to find that there was only relative chaos, and only where State enterprise was concerned. Once in contact with people in the Universities and other places that had only known through correspondence or through mutual friends, I received nothing but overwhelming kindness and generosity. A tour of the great University campus, and its good sports facilities, was followed very early the next morning by a boat trip down the River Ganges past the ghats, slightly put off when a dead body floated past the boat, explained as being possibly a murder, but more likely a poor relative whose salvation should be ensured by being

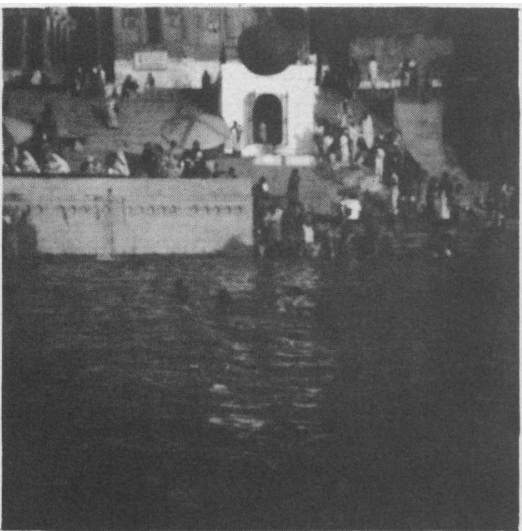

The bathing ghats at Varanasi (Benaras), the holy Hindu city on the River Ganges.

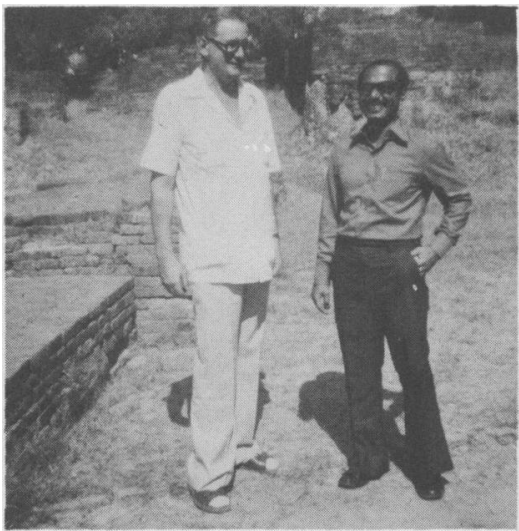

Arun De and Henry Robson in the monastery ruins, Sarnath.

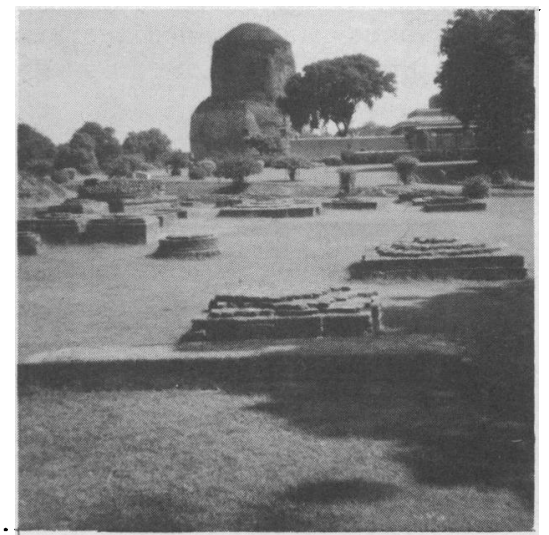

Sarnath, where Buddha preached his first sermon, near Varanasi.

washed in this holy river without the encumbrance of cremation charges. Later a visit was made to Sarnath, the place where Buddha preached his first sermon. In the afternoon I found that I was scheduled to give an open University lecture instead of leading a small seminar for the staff and students of the Unit, but there was an attentive and polite audience of 150 from many departments of the Institute and other faculties. The visual aids were not very good, a lowpowered projector, and a greasy blackboard, but this is far from unknown in U.K. establishments, and none seemed to 